\title{
Anti-tumor immunostimulatory effect of heat-killed tumor cells
}

\author{
Taek Joon Yoon ${ }^{1,4 *}$, Ji Yeon $\mathrm{Kim}^{1,2 \star}$, \\ Hyojeong Kim ${ }^{3 *}$, Changwan Hong ${ }^{2}$, \\ Hyunji Lee ${ }^{2}$, Chang-Kwon Lee ${ }^{5}$, \\ Kwang Ho Lee ${ }^{6}$, Seokmann Hong ${ }^{3,7}$ \\ and Se-Ho Park ${ }^{2,7}$ \\ ${ }^{1} \mathrm{MD}$ Bioalpha Inc. \\ Suwon 443-813, Korea \\ ${ }^{2}$ School of Life Science and Biotechnology \\ Korea University \\ Seoul 136-701 Korea \\ ${ }^{3}$ Department of Bioscience and Biotechnology \\ Institute of Bioscience, Sejong University \\ Seoul 143-747, Korea \\ ${ }^{4}$ Department of Food and Nutrition \\ Yuhan College \\ Bucheon 442-749, Korea \\ ${ }^{5}$ Department of Physiology \\ ${ }^{6}$ Bio-Food and Drug Research Center \\ Department of Biotechnology, Faculty of Life Science \\ College of Natural Science \\ Konkuk University, Chungju 380-701, Korea \\ ${ }^{7}$ Corresponding authors: Tel, 82-2-3290-3160; \\ Fax, 82-2-927-9028; E-mail, sehopark@ korea.ac.kr (for S.H.P.) \\ Tel, 82-2-3408-3649; Fax, 82-2-465-4187; \\ E-mail, shong @ sejong.ac.kr (for S.H.) \\ *These authors contributed equally to this work.
}

Accepted 2 January 2008

Abbreviations: B16, B16-BL6 melanoma; B6, C57BL/6; Colon26, colon 26-M3.1 carcinoma; FF, formaldehyde fixed; FT, freezethawed; HK, heat-killed; L5178Y, L5178Y-ML25 lymphoma

\footnotetext{
Abstract

As a part of our ongoing search for a safe and efficient anti-tumor vaccine, we attempted to determine whether the molecular nature of certain tumor antigens would influence immune responses against tumor cells. As compared with freeze-thawed or formaldehyde-fixed tumor antigens, heat-denatured tumor antigens elicited profound anti-tumor immune responses and greatly inhibited the growth of live tumor cells. The heat-denatured tumor antigens induced a substantial increase in the anti-tumor CTL response in the absence of any adjuvant material. This response appears to be initiated by strong activation of the antigen-presenting cells, which may recognize heat-dena-
}

tured protein antigens. Upon recognition of the heat-denatured tumor antigens, macrophages and dendritic cells were found to acutely upregulate the expression of co-stimulatory molecules such as B7.2, as well as the secretion of inflammatory cytokines such as IL-12 and TNF- $\alpha$. The results of this study indicate that heat-denatured tumor extracts might elicit protective anti-tumor adaptive immune responses and also raise the possibility that a safe and efficient adjuvant-free tumor vaccine might be developed in conjunction with a dendritic cell-based tumor vaccine.

Keywords: cancer vaccines; dendritic cells; immunotherapy, active; interleukin 12; mice

\section{Introduction}

A great deal of research has been conducted in order to develop tumor vaccines, targeted ultimately toward a cure for disease predicated on the induction of anti-tumor immunity (Rosenberg et al., 2004; Emens, 2006; Gattinoni et al., 2006). However, thus far, a safe, efficient, and clinically applicable method has yet to be developed. The principal difficulty inherent to cancer immunotherapy involves the immune escape mechanism, or poor immunogenicity, of tumors (Ahmad et al., 2004; Seliger, 2005). More specifically, the expression of class I- and II-major histocompatibility complex MHC proteins is frequently suppressed in tumors (Garcia-Lora et al., 2003; Ogino et al., 2003; Vitale et al., 2005). Tumor antigens can be hidden by muco-polysaccharides harboring sialic acid, which inhibits the function of CTL and helper $T$ cells (Gutzmer et al., 2004). Moreover, as tumor cells do not express co-stimulatory signals that stimulate $T$ cells, it remains possible that $T$ cells can become anergic upon their initial recognition of tumor antigens (Hirst et al., 1997; Appleman and Boussiotis, 2003; Cuenca et al., 2003). Tumor cells also express TGF- $\beta$, which has an immunosuppressive function. Additionally, they can express Fas, which could potentially result in the inactivation of effector cells such as CTLs (Toutirais et al., 2003; Witham et al., 2003; Li et al., 2005).

Unfortunately, the tumor-specific antigens of many tumor cell types have yet to be definitively identified. Since effective immunity is not solely induced by any known tumor antigen, researchers anticipate that a multivalent antigen, simultaneously utilizing at least three antigens for immuniza- 
tion, may effectively induce an adequate anti-tumor immune response. Thus, current research is focusing on the immune response generated by a whole tumor vaccine. The known vaccine types utilized as whole tumor cells are as follows: apoptotic cells, freeze/thawed necrotic cells, irradiated cells, formaldehyde-fixed cells, heat shock proteins, and photoreactive or photosensitized cells (photodynamic therapy: PDT), among others (Prasad et al., 2005; Cheuk et al., 2006; Copier and Dalgleish, 2006; Korbelik and Sun, 2006).

Effector cells involved in anti-tumor immunity can be subdivided into the following categories: tumorspecific helper $\mathrm{T}$ cells, cytotoxic $\mathrm{T}$ lymphocytes, tumor-nonspecific macrophages, NK-cells, and NKT cells. CTL, which are involved in cell-mediated immunity, are the best known anti-tumor effector cells. Anti-tumor CTL activity is induced principally via the recognition of MHC-I presenting tumor antigen on APC, including dendritic cells (DCs) and macrophages (Chang, 2006). Accordingly, a significant amount of attention is currently focused on an immunization technique in which DCs are used as a professional APC (NouriShirazi et al., 2000a; Paczesny et al., 2003; Banchereau and Palucka, 2005). In the in vivo mechanism by which immunity is conferred by a tumor vaccine for the treatment or prevention of malignant tumors, the induction of antigen-presenting ability by DCs and macrophages, used as professional APCs, is regarded as the most salient factor. In previous studies, several researchers have reported the co-culturing of DCs or macrophages with apoptotic or necrotic tumor cells as a tumor vaccine, followed by their inoculation into a tumorbearing host, thereby inducing a significant inhibition of both tumor proliferation and metastasis (Banchereau et al., 2000; Nouri-Shirazi et al., 2000b; Avigan, 2004; Prasad et al., 2005). These results appeared to indicate that the immune escape mechanism of tumors, as previously mentioned, might be circumvented via the use of strong APCs for the induction of tumor antigen presentation. For this reason, research into the use of immune adjuvants, cytokines or their receptors, and tumor cells that have been genetically manipulated to improve cancer antigen presentation ability, is being conducted (Hirst et al., 1997; Witham et al., 2003; Gattinoni et al., 2006; Hong et al., 2006). This research is ultimately intended to enhance immunity against poorly-expressed cancer antigens. However, the majority of adjuvants employed in animal experiments exhibit prominent side effects, and is not recommended for human injection. Thus, efforts to find strong, but safe adjuvants are clearly required.
In the present study, we have investigated the anti-tumor effects of a whole tumor vaccine in the form of heat-killed (HK) tumor cells. In addition to its ease of preparation and overall safety, this vaccine has been shown to elicit a profound antitumor immune response and also substantially inhibited the growth of live, injected tumor cells. Moreover, the HK vaccine inhibited the growth of pre-implanted tumor cells. Our results indicate that heat-denatured tumor specific protein antigens may elicit protective anti-tumor adaptive immune responses and also raises the possibility that more safe and efficient adjuvant-free tumor vaccines might be developed.

\section{Materials and Methods}

\section{Animals, cell lines and antibodies}

Wild-type Balb/c, C57BL/6 (B6), and DBA/2 F1 (CDF1) mice were purchased from Charles River Japan Inc. (Yokohama, Japan) and were housed in a specific pathogen-free environment. Experiments were conducted in accordance with the guidelines established by the Animal Care and Use Committee of Korea University. The Colon 26-M3.1 carcinoma (Colon26), B16-BL6 melanoma (B16), and L5178Y-ML25 lymphoma (L5178Y) cell lines were maintained in RPMI 1640 complete medium (Life Technologies, Grand Island, NY) supplemented with $10 \%$ heat-inactivated FBS (Hyclone, Logan, UT), $2 \mathrm{mM}$ L-glutamine, $50 \mathrm{U} / \mathrm{ml}$ penicillin, $50 \mu \mathrm{g} / \mathrm{ml}$ streptomycin, $10 \mu \mathrm{g} / \mathrm{ml}$ gentamycin sulfate, and $5 \mu \mathrm{M} \beta$-mercaptoethanol (all from Life Technologies, Grand Island, NY). The anti-asialoGM1 polyclonal antibody was obtained from Wako Chemicals (Osaka, Japan). Control rabbit polyclonal serum was purchased from Sigma (St Louis, MO). A HRP-conjugated anti-mouse IgG antibody (from Sigma) was used to measure serum anti-tumor IgG levels. The anti-HSP70 antibody for Western blotting was purchased from Stressgen (Victoria, BC, Canada).

\section{Preparation of tumor vaccines}

Cells were harvested and washed three times with PBS in order to remove any serum contaminants. The cells were resuspended at $5 \times 10^{6} / \mathrm{ml}$ in PBS and divided into the following groups: heat-killed (HK), formaldehyde fixed (FF), and freeze-thawed (FT). The HK vaccine was prepared by boiling the cells for $30 \mathrm{~min}$. The FF vaccine was prepared by incubating cells for $24 \mathrm{~h}$ in $0.1 \%$ formaldehyde in PBS, followed by washing with PBS. The FT vac- 
cine was prepared by freezing tumor cells in liquid nitrogen and thawing at room temperature (three times). All vaccines were prepared to have identical final cell concentrations of $5 \times 10^{6} / \mathrm{ml}$ in PBS, regardless of the preparation method.

\section{Immunization and tumor challenge}

Each mouse was immunized subcutaneously (s.c.) with $100 \mu \mathrm{l}$ of a tumor vaccine, which is equivalent to $5 \times 10^{5}$ cells, two or three times at two-week intervals. No adjuvants were used in the immunization. Two weeks after the final immunization, 5 $\times 10^{4}$ live tumor cells were injected intravenously (i.v.) into immune and non-immune mice for the enumeration of metastatic tumor nodules in the lungs. Two weeks after tumor injection, the mice were sacrificed and their lungs were fixed for 30 min in Bouin's solution prior to tumor counting. In order to measure solid tumor growth, the tumor cells were injected s.c. and the sizes of the tumors were calculated as the multiplication of the length and width of the tumor mass. The tumor bearing livers were weighed after hepatic metastasis of the tumor. The tumor challenge data shown in this study are representative of two or three independent experiments in which each of the experimental groups contained 5-8 mice.

\section{Flow cytometric (FACS) analysis and monoclonal antibodies}

Cells were re-suspended in FACS staining buffer (PBS containing $0.1 \%$ BSA and $0.01 \%$ sodium azide), incubated for $20 \mathrm{~min}$ at $4^{\circ} \mathrm{C}$ with an anti-FcR- $\gamma$ monoclonal antibody $2.4 \mathrm{G} 2$, and finally stained for $30 \mathrm{~min}$ with the appropriate mAbs labeled with biotin, FITC, R-phycoerythrin (PE), Cy-chrome, or Allophycocyanin. In cases in which biotinylated mAbs were used, streptavidin-PE or streptavidin-Allophycocyanin were used as secondstep reagents. mAbs against CD3 $\varepsilon$ (clone 2C11), CD4 (clone RM4-5), CD8 (clone 53-6.7), CD11b (clone M1/70), CD11c (clone HL3), CD19 (clone ID3), CD69 (clone H1.2F3), CD86 (clone GL-1), and anti-NK (DX5) (all from BD PharMingen) were used. The antibody-stained cells were then analyzed on a FACSCalibur system using CELLQuest ${ }^{\mathrm{TM}}$ software (both BD Biosciences).

\section{Depletion of immune cells}

Mice were injected on days -3 and -1 with $200 \mu \mathrm{g}$ purified GK1.5 anti-CD4 mAb, 2.43 anti-CD8 mAb or control isotype-matched 14.4.4.S anti-I- $E^{\mathrm{k}} \mathrm{mAb}$ for the depletion of $C D 4^{+} \mathrm{T}$ cells or $\mathrm{CD}^{+} \mathrm{T}$ cells, respectively. For the depletion of NK cells, anti-
asialoGM1 or control polyclonal rabbit serum was injected. Depletion was monitored by staining with anti-CD3 and anti-CD4, anti-CD8, or anti-DX5.

\section{Cell proliferation, cytokines, and CTL assay}

Cell proliferation after antigen stimulation was measured by the cell counting kit-8, which is based on the reduction of colorless tetrazolium salt to the colored formazan dye by electron mediators of live cells (Dojindo Laboratories, Kumamoto, Japan). The OD of the reactant was read using a Bio-Rad microplate reader at $450 \mathrm{~nm}$.

Peritoneal macrophages and dendritic cells were extracted from the peritoneal cavities of mice injected with $3 \mathrm{ml}$ of $3 \%$ thioglycollate for 3 days and 50 $\mathrm{mg} / \mathrm{kg}$ body weight of silica (amorphous, particle size 0.5-10 $\mu \mathrm{m}$, Sigma-Aldrich) for $24 \mathrm{~h}$, respectively. Washed cells were plated at $1 \times 10^{6}$ cells/ well in a 96-well plate and incubated for $2 \mathrm{~h}$. After washing out any unbound cells with culture medium, antigens were added at different concentrations. After $24 \mathrm{~h}$ of incubation, the culture medium was harvested and the cytokines were detected using sandwich ELISA kits (BD PharMingen). The cells were collected and subsequently analyzed via flow cytometry for surface antigen expression.

Spleen cells were harvested from mice 14 days after immunization and then were re-stimulated in vitro with $20 \mathrm{U} / \mathrm{ml}$ of recombinant human IL-2 (rhIL-2, PeproTech, Cytolab, Ltd.) plus tumor cell extracts for 5 days. Effector cells were then harvested, washed, and adjusted to a concentration of $10^{6} \mathrm{cells} / \mathrm{ml}$ and a varying number of effector cells were added to live $\left[{ }^{3} \mathrm{H}\right]$-thymidine-labeled target tumor cells $\left(1 \times 10^{4}\right.$ cells/well) in 96-well roundbottomed plates at the desired $\mathrm{E}: \mathrm{T}$ ratios (Matzinger, 1991; Hong et al., 2006). Each plate included 12 wells of target cells alone as a control. After $7 \mathrm{~h}$ of incubation at $37^{\circ} \mathrm{C}$ in a humidified atmosphere with $5 \% \mathrm{CO}_{2}$, the culture plates were frozen and thawed three times, then harvested and measured with a micro-beta counter (Wallac Inc., Turku, Finland). The mean percentage specific lysis of triplicate wells was calculated as following: \% specific lysis $=[(\mathrm{cpm}$ spontaneous value-cpm experimental value)/cpm spontaneous value] $\times 100$. The cytokine profiles and CTL activities shown in the results are representative of at least two independent experiments.

\section{Results}

\section{Whole cell tumor vaccines}

We immunized wild-type Balb/c mice subcuta- 
neously with different types of tumor vaccines prepared from Balb/c-derived colon26-M3.1 carcinomas. The mice were immunized twice at twoweek intervals and $5 \times 10^{4}$ live tumor cells were injected intravenously two weeks after the final immunization. On day 14 after the initial tumor injection, the mice were sacrificed and metastatic tumor nodules in the lung were counted. To our surprise, mice immunized with the HK tumor vaccine showed almost no metastatic tumor growth in the lung. However, it was determined that the unimmunized mice harbored greater than one hundred growing tumor nodules and the FT vaccinated mice exhibited slightly inhibited tumor cell growth. The FF vaccine also inhibited tumor growth, but was far less effective than the HK vaccine (Figure $1 \mathrm{~A})$.

\section{General effects of the HK vaccine in different cell lines, mouse strains, and immunization route}

We attempted to determine whether this protective
A

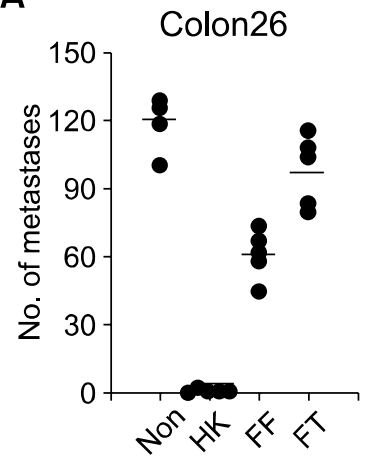

B

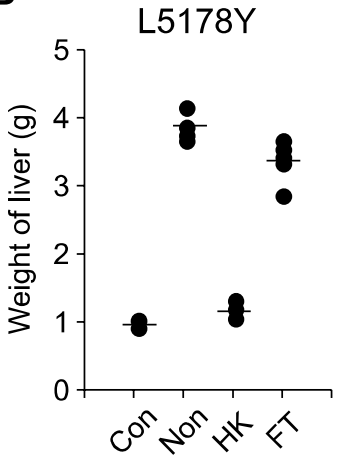

C

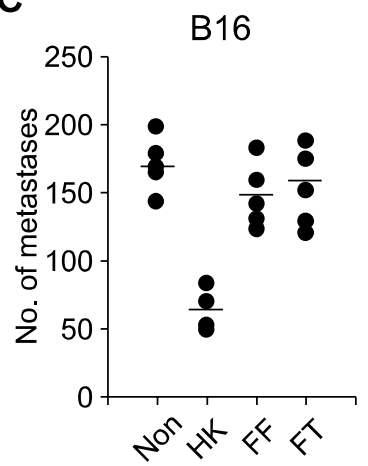

Figure 1. Anti-tumor effects of the HK vaccine. Mice were subcutaneously immunized three times each at 2-week intervals with $100 \mu$ of heat killed (HK), formaldehyde-fixed (FF), or freeze-thawed (FT) tumor vaccines, or un-immunized (Non). Two weeks after the final immunization, $5 \times 10^{4}$ live tumor cells were i.v. injected and tumor metastasis was assessed 2 weeks after tumor challenge. (A) Balb/c mice immunized and challenged with colon 26-M3.1 (Colon26) tumor cells. (B) CDF1 mice immunized and challenged with L5178Y-ML25 (L5178Y) tumor cells. The size of the liver is expressed as weight of each liver. Normal livers from naïve mice were weighed as controls (Con). (C) C57BL/6 mice immunized and challenged with B16-BL6 (B16) cells. Horizontal bars represent average values in each experimental group.

A

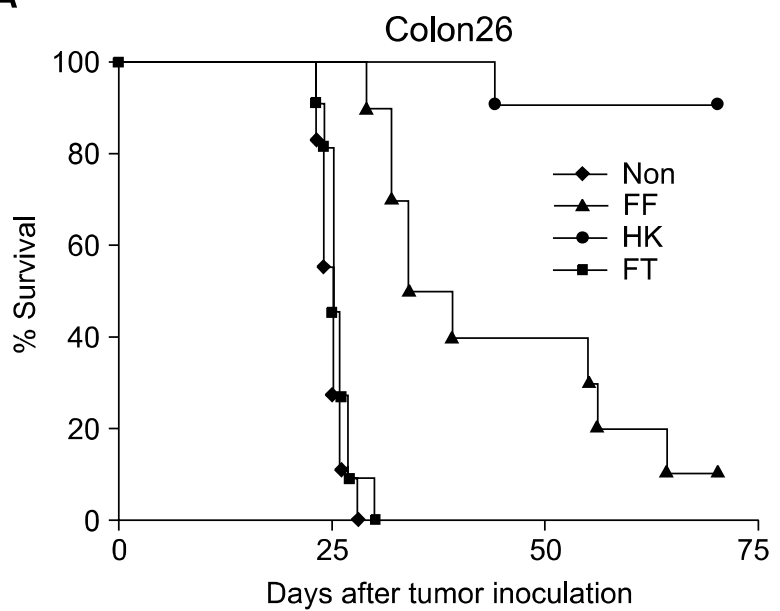

B

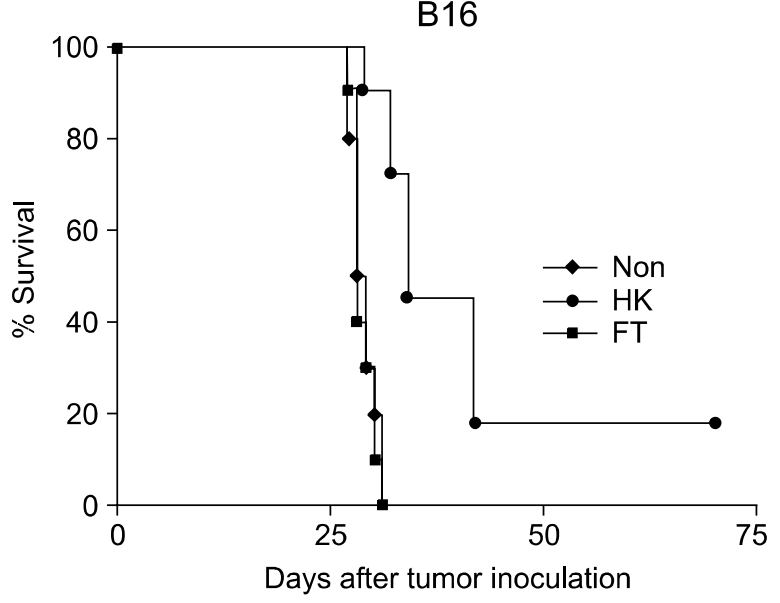

Figure 2. Enhanced survival of HK vaccine-immunized mice. Mice immunized and challenged as shown in Figure 1 were monitored for their survival. (A) The survival of Balb/c mice immunized with the indicated types of Colon 26 vaccines. (B) The survival of B6 mice immunized with the indicated types of B16 melanoma vaccines. 
effect of the HK tumor antigen immunization represented a general phenomenon rather than an abrupt, unexpected effect of the Colon26 cell line or a restricted effect of the lung metastasis model. In order to confirm the anti-tumor effects of the HK vaccine on different mouse strains and tumor models, we prepared HK tumor vaccines with B6derived B16 and CDF1-derived L5178Y tumor cells using the same protocols as described above, and then immunized B6 or CDF1 mice with these vaccines. Live B16 and L5178Y tumor cells were injected i.v. to induce metastasis to the lung and liver, respectively. Regardless of the mouse strains and tumor cell lines, mice immunized with HK

A

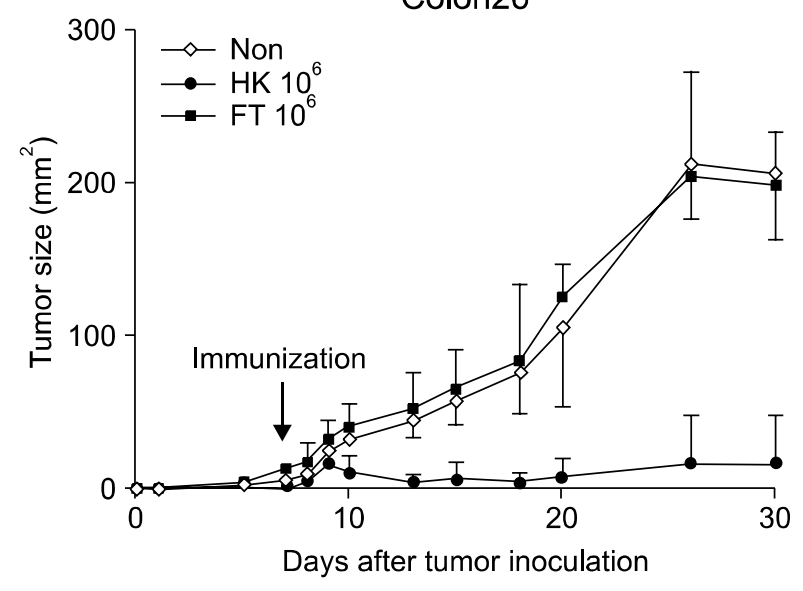

C

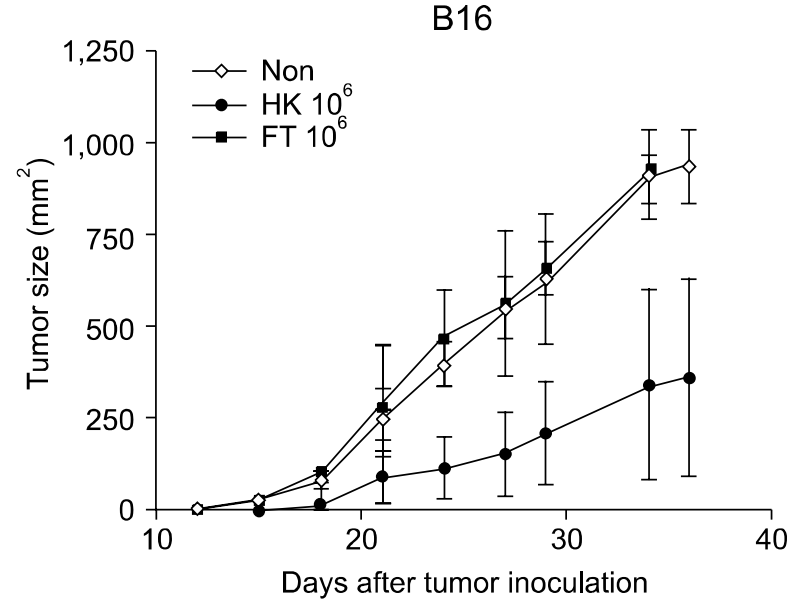

tumor vaccines, but not with the FT vaccine, showed a dramatic reduction in tumor growth in the liver (in the case of L5178Y) and lung (B16) upon challenge with live tumors (Figure $1 B$ and $C$ ). Survival rates of both the Balb/C and $B 6$ mice immunized with $\mathrm{HK}$ vaccines were greater than the mice immunized with FT or FF vaccines upon live tumor challenge (i.v.) (Figure 2). Because both of $\mathrm{FT}$ and $\mathrm{FF}$ vaccines were inferior in their effect on tumor rejection compared to HK vaccine, we used $\mathrm{FT}$ vaccine alone as a control vaccine of $\mathrm{HK}$ vaccine here after.

We also attempted to assess the anti-tumor effects of the HK vaccine using a subcutaneous

B

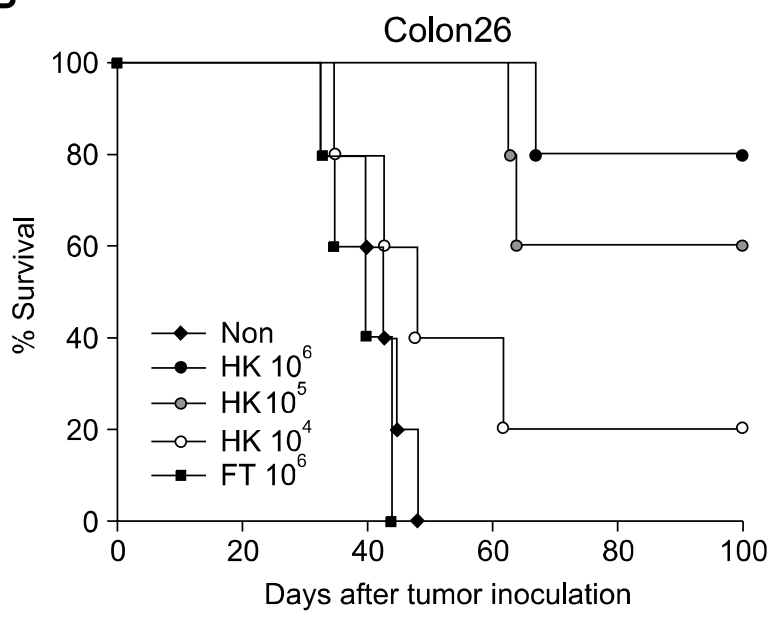

D

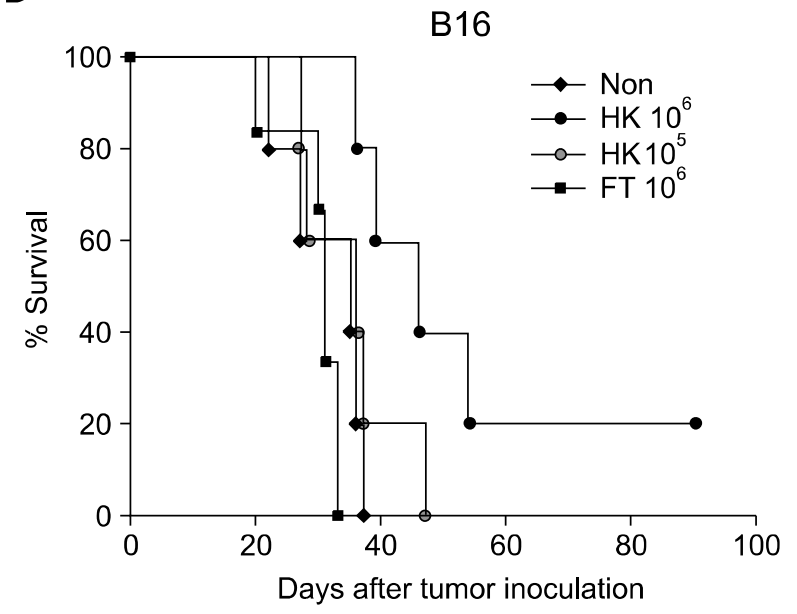

Figure 3. Anti-tumor effects of the HK vaccine in subcutaneously challenged tumors. Mice were immunized as in Figure1 and were challenged with $5 \times 10^{4}$ live tumor cells subcutaneously injected into the flank. Balb/c mice challenged with Colon26 (A, B) and B6 mice challenged with B16 melanoma (C, D) were subjected to measurements of tumor growth $(A, C)$ and survival $(B, D)$. Different doses of the HK tumor vaccine range from $1 \times 10^{4}-10^{6}$, were utilized for immunization. 
tumor growth model in Balb/c and B6 strains. As compared to the FT vaccine, the HK vaccine dramatically inhibited subcutaneous tumor growth in both mouse strains (Figure $3 \mathrm{~A}$ and $\mathrm{C}$ ). The HK immunized mice showed greater survival rates than the mice immunized with other types of vaccine and some of them survived up to day 100 after tumor challenge (Figure 3B and D). However, there were some differences in tumor growth and survival rates between the $\mathrm{B} 16 \mathrm{HK}$ and Colon26 $\mathrm{HK}$ vaccine treated groups, in which a lower overall protection range was measured against B16 melanoma than Colon26 carcinoma cells (Figure $3 \mathrm{~B}$ and $\mathrm{D}$ ).

The inhibitory effects of the HK vaccine on tumor growth were found to depend on the immunization dosage of tumor antigen. This was determined by measuring the survival rates of mice immunized with different doses of HK vaccine. While the FT vaccine did not extend the survival of the mice as compared to the unimmunized control group, 20$80 \%$ of the HK vaccine-immunized mice, depending on the immunization dosage $\left(1 \times 10^{4}\right.$ to $1 \times$ $10^{6}$ cells), survived for at least 100 days after tumor injection (Figure 3B and D). Additionally, we observed no signs of growing tumors among the mice surviving until day 100 .

These results indicate that the anti-tumor effects of the HK vaccine were evoked as a result of the antigen preparation method rather than antigenic determinants which reside in the tumor cell itself, as the same antigen prepared by repeated freezing and thawing did not elicit any protection at all. Moreover, this protective effect was not dependent on the mouse strains, tumor cell lines, or tumor inoculation sites.

\section{Effector mechanism}

As we included no adjuvant materials in the va-
A

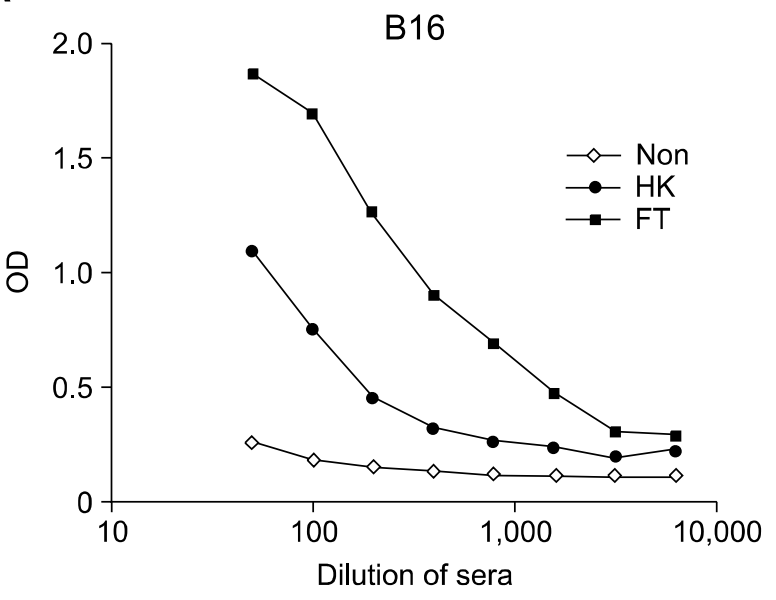

B

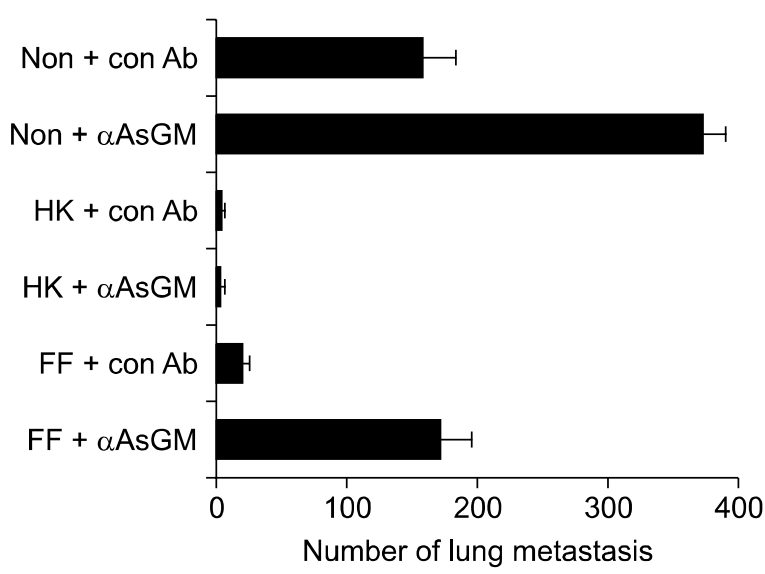

Figure 4. The effect of the HK vaccine on the tumor-specific antibody response and NK cell responses. (A) Anti-tumor antibody response; sera were collected from mice immunized with the respective vaccines and challenged with live tumor cells 2 weeks after live tumor injection. Adherent live tumor cells (B16 melanoma and Colon26 tumor cells) were cultured on 96-well plates and were employed to serve as antigens for the measurement of tumor-specific lgG by sandwich ELISA. HRP-conjugated anti-mouse lgG antibody was used as a detection antibody. (B) Depletion of NK cells; immunized and unimmunized Balb/c mice were treated with either control (con Ab) or anti-asialoGM1 $(\alpha$ AsGM) antibodies, as described in the Materials and Methods, prior to the injection of Colon26 tumor cells. Lung metastasis was counted 2 weeks after tumor injection. 
ccine, with the exception of differing physical methods for the preparation of the tumor cell extract, it appears likely that the heat-killing of tumor cells makes tumor antigens more likely to elicit protective anti-tumor immune responses. It seems possible that stress-induced proteins might be activated during antigen preparation and may influence immune responses against tumor antigens. The Heat Shock Protein (HSP) family stimulates the production of $\mathrm{IL}-12$ and induces Th1 immune responses that are important effector mechanisms of anti-tumor immune responses (Todryk et al., 1999; Wang et al., 2002). We analyzed whether the process of HK preparation induced higher HSP production than the processes of $\mathrm{FT}$ preparation. While FT and $45^{\circ} \mathrm{C}$ heated tumor cells expressed heat shock protein 70 (HSP70), the HK preparation did not show evidence of HSP70 expression by immunoblotting with an anti-HSP70 antibody (data not shown). It is very likely that the immediate boiling of the tumor cells does not allow any new gene expression.

We also attempted to determine whether the HK vaccine was capable of inducing enhanced antitumor antibody responses. Serum antibody levels against tumor cell antigens were measured in mice immunized with the $\mathrm{HK}$ and $\mathrm{FT}$ vaccines. The HK vaccine induced anti-tumor cell antibody production to levels that were slightly lower than those associated with the FT vaccine, which is not protective against tumor growth and induces no significant improvements in mouse survival rates (Figure 4A).

Another possible explanation for the underlying mechanism of the HK vaccine-induced anti-tumor effect is the involvement of NK cells. We attempted to determine whether the HK vaccine effect depends on NK cell involvement by depleting NK cells from immunized mice. Since FF vaccine unlike FT vaccine showed modest tumor rejection effect in the lung metastasis model of Colon26 tumor cells (Figure 1A), we used FF vaccine as a control group instead of FT in this particular experiment. Unimmunized mice treated with anti asialoGM1 antibodies developed around three times as many tumor nodules as did unimmunized control Ab-treated mice, thereby indicating the role of NK cells in immune surveillance and also the successful depletion of NK cells in antibody-treated mice. The FF vaccine-immunized mice also produced similar patterns of increased tumor metastasis when the NK cells were depleted. However, the anti-asialoGM1 treated $\mathrm{HK}$-immunized mice were protected against lung tumor growth, as was seen with the mice immunized with intact NK cells. This result precludes the possibility of any major role of NK cell-dependent anti-tumor effects at least in the primary immunization phase in mice immunized with the $\mathrm{HK}$ vaccine (Figure 4B).
A

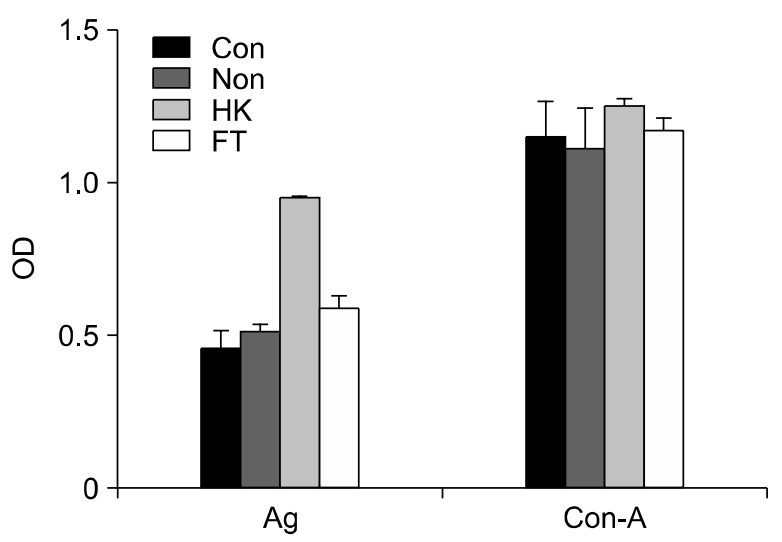

B

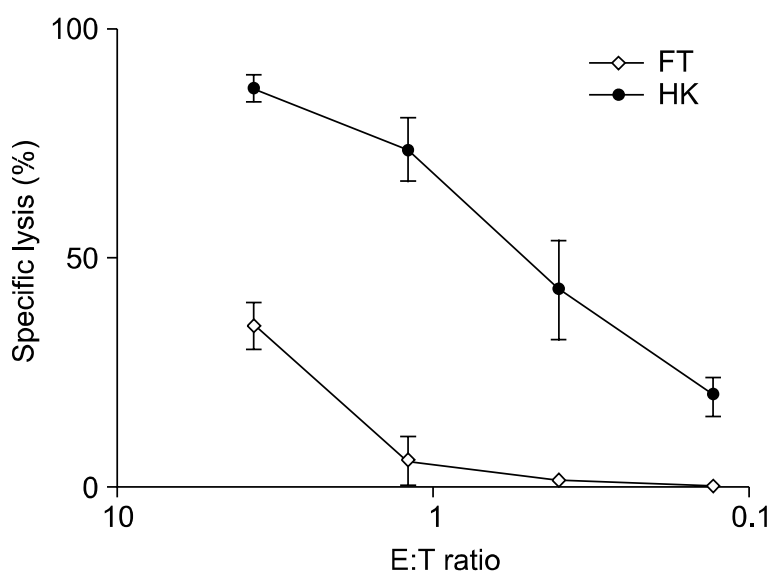

Figure 5. Tumor-specific cytotoxicity. Splenocytes from mice immunized with the indicated tumor vaccines and injected with tumor cells were harvested 2 weeks after live tumor injection, as described in the Materials and Methods section. (A) $1 \times 10^{5}$ cells were incubated for $24 \mathrm{~h}$ with FT tumor extract equivalent to $5 \times 10^{4}$ cells prior to the cell proliferation assay as in the Materials and Methods. Values of wells to which only tumor extract was added were considered background and were subtracted from the experimental values for the purpose of comparison. The scale is OD values. The experimental groups unimmunized and no tumor challenged (con); tumor injected without immunization (Non), tumor challenged after HK-immunization (HK), and FT-immunization (FT) were analyzed. (B) Cytotoxic T cell responses were determined with the effector cells from the FT or HK immunized mice. Varying numbers of the effector cells were incubated with $1 \times 10^{4}\left[{ }^{3} \mathrm{H}\right]$-thymidine-labeled Colon26 target cells for 8-12 $\mathrm{h}$ and the cytotoxicity was evaluated as described in the Materials and Methods section. 


\section{Induction of cytotoxic $\mathrm{T}$ cell responses}

By excluding the major involvement of $B$ cells and NK cells in HK vaccine-induced anti-tumor responses, we assumed that anti-tumor $\mathrm{T}$ cell responses might be strongly induced in the HK-immunized mice, but not in the FT immunized mice. Mice immunized with HK, FT, or PBS were subjected to i.v. challenge with Colon26 tumor cells and their splenocytes were collected on day 14 after tumor injection. The cells were stimulated with FT tumor antigen in order to quantify antigen-specific $T$ cell proliferation. The splenocytes from HK-immunized mice showed prominent cell proliferation by the MTT assay, but the splenocytes from FT or PBSimmunized mice produced relatively weak responses similar to those of the splenocytes from naïve mice (Figure 5A). The splenocytes from all four groups maintained normal $\mathrm{T}$ cell responses, as they showed similar cell proliferation when treated with the mitogenic $T$ cell activator concanavalin-A (Con-A).

We then attempted to determine whether these antigen-specific $T$ cells might be directly responsible for tumor cell rejection. In order to measure cytotoxic lymphocyte activity, we evaluated cytotoxic $\mathrm{T}$ lymphocyte activity against $\left[{ }^{3} \mathrm{H}\right]$-thymidinelabeled Colon26 tumor cells. The $T$ cells from HK-immune mice exerted a profound killing effect against Colon26, which was used in the immunizations of the mice. However, the T cells from the FT-immunized mice, which were used as a negative control, did not generate strong CTL responses (Figure 5B).

We then assessed cytokine production in antigen restimulated splenocytes in vitro. Mice were injected with live tumor cells without immunization and their spleens were obtained two weeks after tumor injection. The production of IFN- $\gamma$ after the in
A

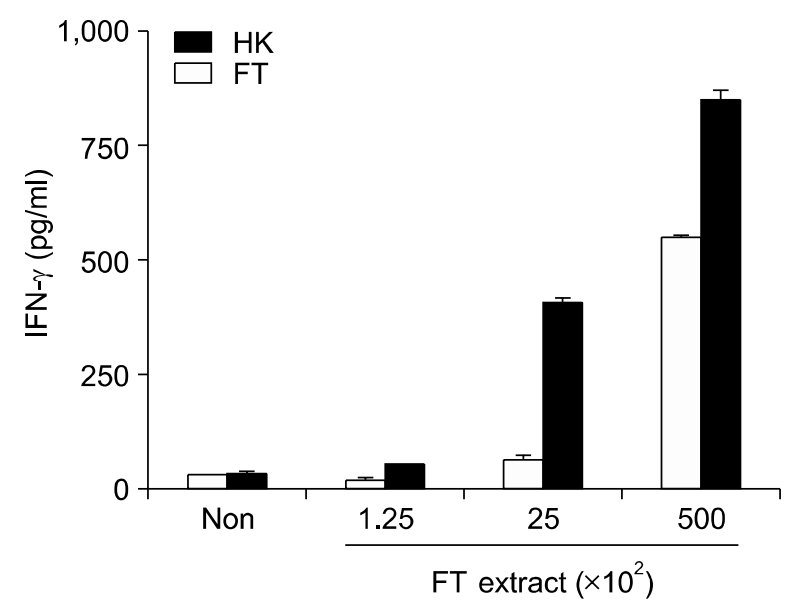

B

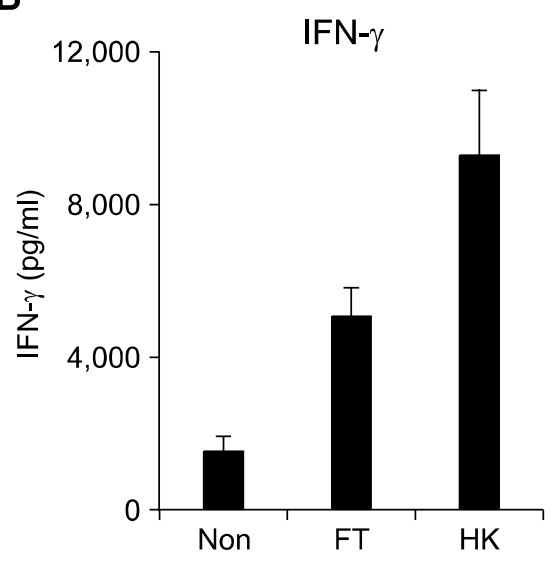

E

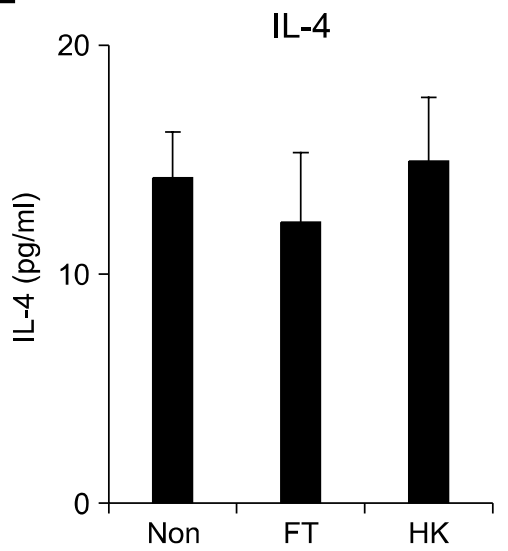

C

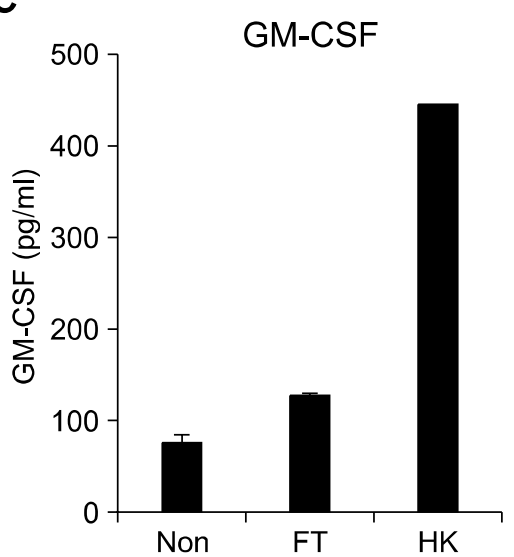

D

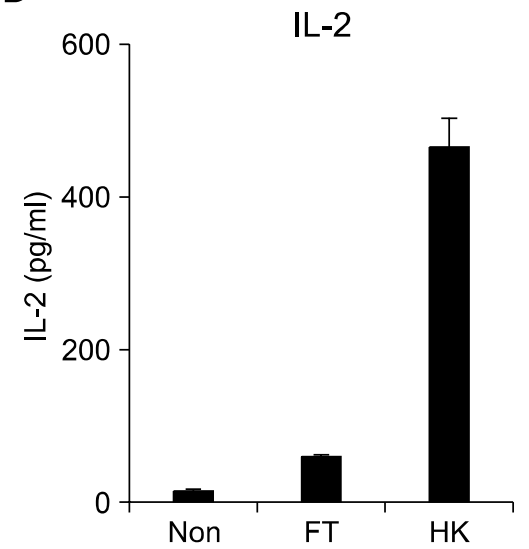

Figure 6. HK vaccine effects on IFN- $\gamma$ production. $1 \times 10^{5}$ splenocytes prepared as in Figure 5 were incubated for $24 \mathrm{~h}$ with varying amounts of FT extract $(A)$ and with $1 \times 10^{5}$ live tumor cells $(B-E)$, and the culture supernatants were collected for cytokine measurements via sandwich ELISA. 
vitro re-stimulation of whole splenocytes with different amounts of either FT or HK tumor extracts resulted in antigen dose-dependent IFN- $\gamma$ production in both the HK and FT-restimulated splenocytes. However, the HK-restimulated cells generated more IFN- $\gamma$ than did the FT-restimulated cells (1.6-9 times depending on antigen doses, Figure $6 A)$.

We conducted a similar experiment for the detection of cytokines in a setting in which in vitro restimulation was elicited by live tumor cells rather than tumor cell extracts. The reason for this was that in cases in which immunized animals are subjected to challenges with live tumor cells, the stimulating antigen is provided either in the form of live tumor cells or its processed forms, rather than in vaccine extract form.

Splenocytes from mice immunized with the FT or $\mathrm{HK}$ vaccine were re-stimulated with live Colon26 cells, after which the levels of IFN- $\gamma$ production were determined. The HK-immunized splenocytes

A

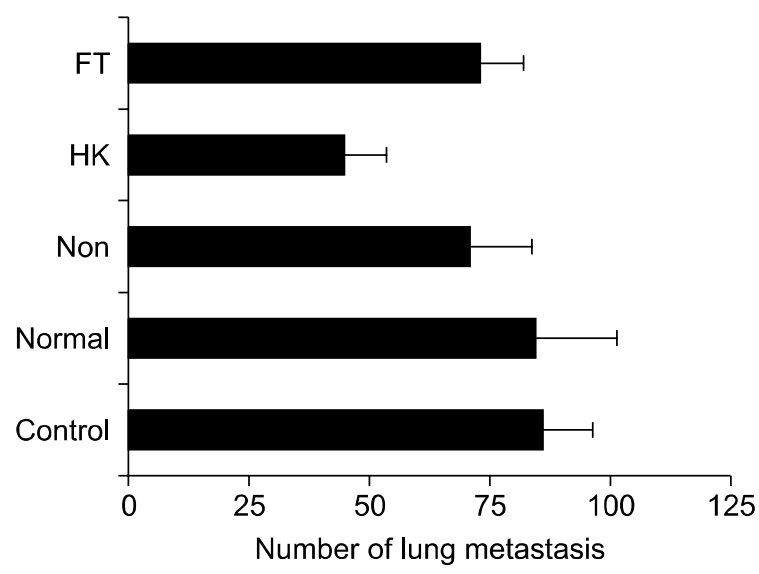

C

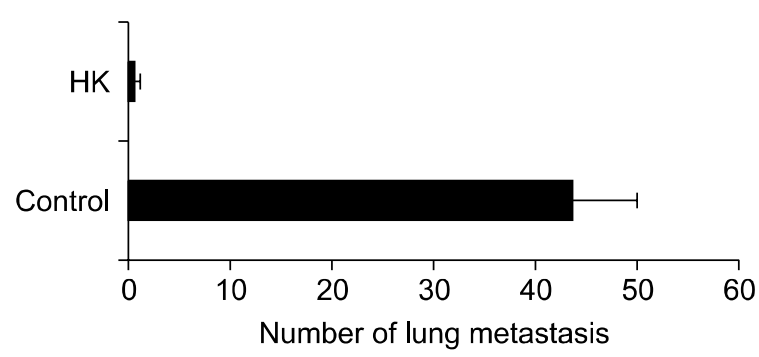

produced a large amount of IFN- $\gamma$ upon tumor cell challenge. Surprisingly, the cells from the FTimmunized mice also generated a large quantity of IFN- $\gamma$, although these quantities were relatively smaller than those observed in the case of HK immunization (Figure 6B). As FT immunization did not efficiently elicit tumor specific cytotoxic responses (Figure 5B) despite IFN- $\gamma$ production, we compared the production of several other cytokines by immunized spleen cells in response to live tumor cell antigen. The HK-immunized cells generated more GM-CSF and $\mathrm{IL}-2$ than did the FTimmunized cells, but both cells generated similar, but minimal quantities of IL-4 (Figure 6C-E).

\section{Induction of memory $\mathrm{T}$ cell responses}

The very effective rejection of tumor cells in mice immunized with the HK vaccine must be accompanied by the generation of tumor antigen-specific adaptive immune responses. We attempted adop-

B

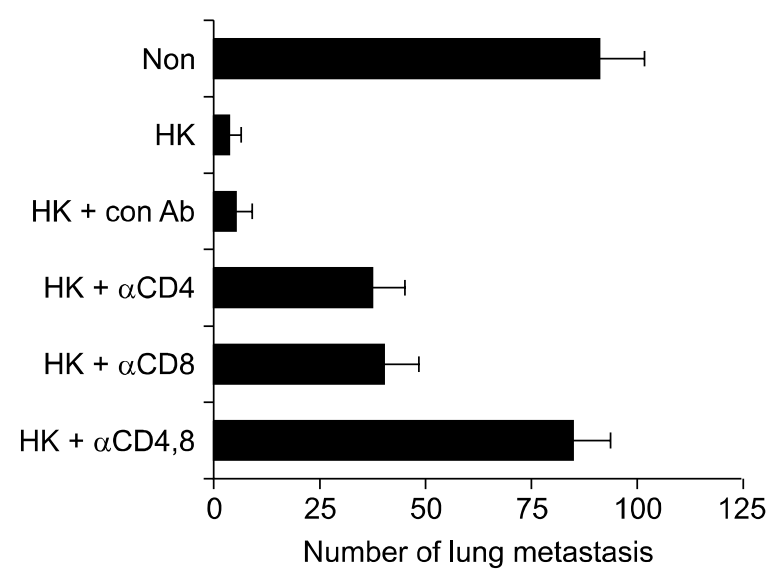

Figure 7. Induction of T cell-mediated anti-tumor immunity by the HK vaccine. (A) Spleen cells from FT or HK vaccine immunized or unimmunized (non) and tumor-challenged mice were prepared 2 weeks after tumor challenge and were transferred (i.v.) to naive Balb/c mice $\left(2 \times 10^{6}\right.$ cells/mouse). Two days after cell transfer, $5 \times 10^{4}$ live tumor cells were i.v. injected and tumor metastasis was measured 2 weeks after tumor challenge. Non-immune spleen cell-received mice (Normal) and mice who had received no spleen cells (Control) were used as positive controls for tumor growth. (B) Mice immunized s.C. with the Colon26 HK vaccine received $200 \mu \mathrm{g} /$ mouse of purified anti-CD4 (GK1.5) and/or anti-CD8 (24.3) or control (14.4.4s) monoclonal antibodies on days -3 and -1 of live tumor injection (i.v.). Unimmunized mice (Non) and mice immunized with HK, but not treated with antibody were used as positive and negative controls for tumor growth on day 14. (C) HK-immunized mice surviving after tumor challenge were re-injected with an identical number of live tumor cells on day 100 of the first tumor challenge and the metastatic tumor nodules were counted 2 weeks after the second tumor challenge. The control group contained tumor-challenged naïve mice. 
tive transfer of immune spleen cells to naïve mice. Mice received unimmunized spleen cells (Normal) did not show any sign of tumor rejection compared to control animals, in which no spleen cells were transferred (Control). Mice receiving spleen cells from the tumor-only challenged (non) and FT
A

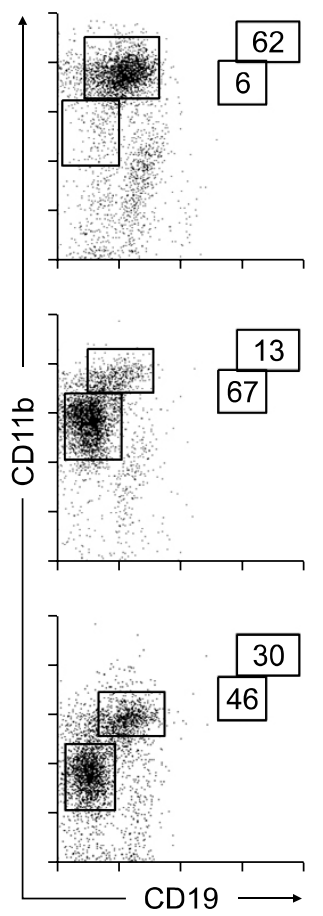

B

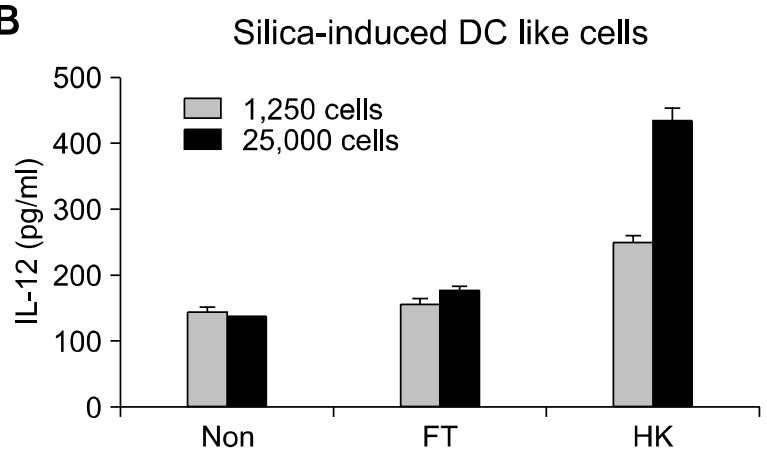

HK

\section{TG-induced macrophages}

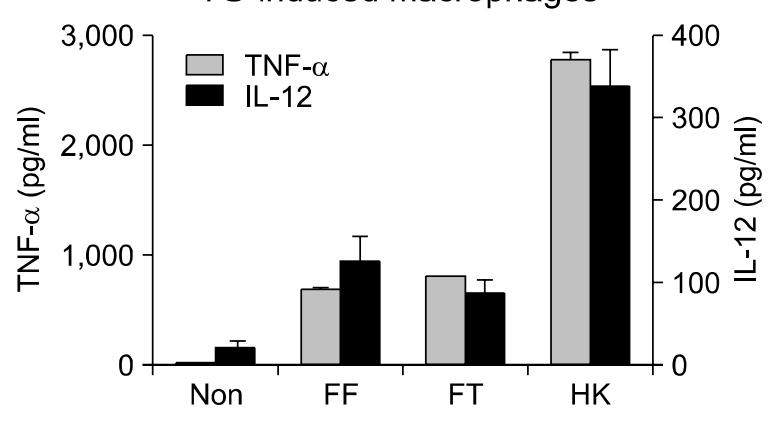

D

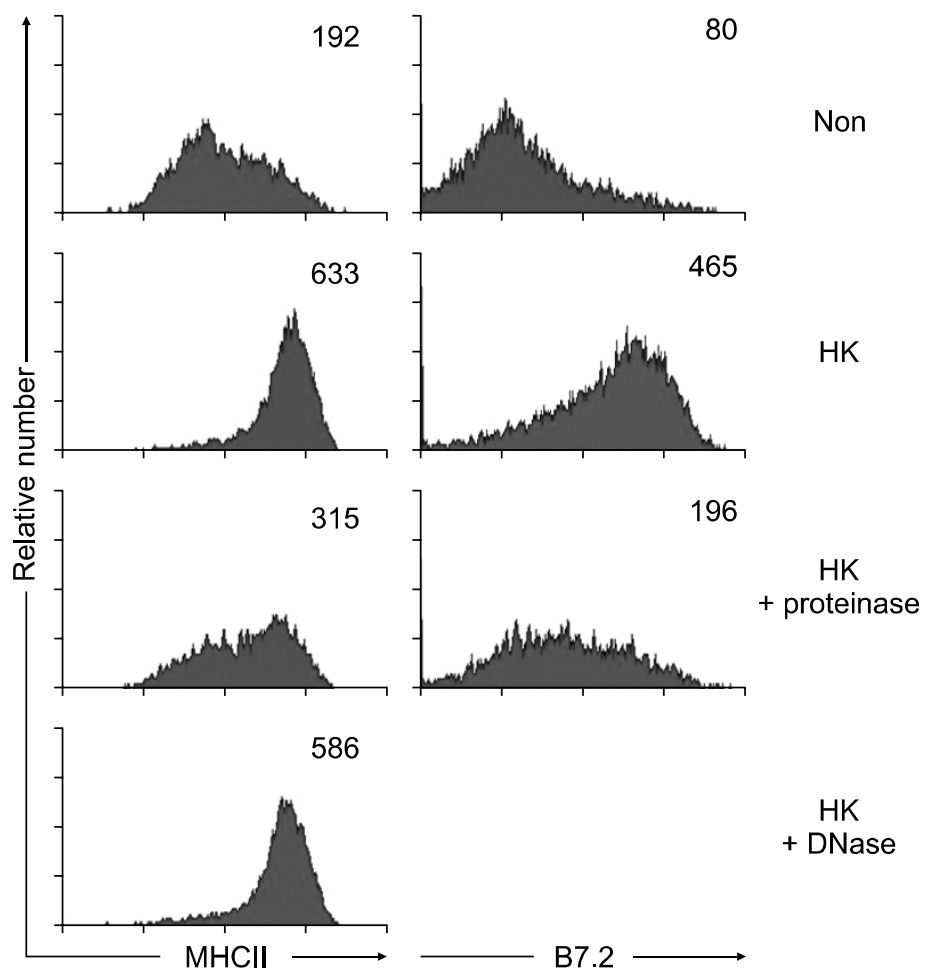

Figure 8. Stimulation of APCs by the HK vaccine. (A) Peritoneal cells from untreated (Non) or $5 \times 10^{5}$ tumor cell equivalent extract (HK or FT)-injected (i.p.) mice were prepared $5 \mathrm{~h}$ after the vaccine injection and were analyzed via flow cytometry. The percentages of CD11 $\mathrm{b}^{+}$ and $\mathrm{CD} 19^{-}$cells are indicated, and their B7.2 expression levels (right panels) are shown. Peritoneal cells prepared as described in the Materials and Methods section using silica (B) and thioglycollate (C) were stimulated with the indicated tumor vaccines equivalent to $5 \times$ $10^{4}$ or a marked number of tumor cells for $24 \mathrm{~h}$ and cytokine production was assessed using the culture supernatants. Splenocytes were stimulated with the HK vaccine, proteinase-treated HK vaccine (100 $\mu \mathrm{g} / \mathrm{ml}$ of each proteinase- $\mathrm{K}$ and pronase, at $40^{\circ} \mathrm{C}$ for $1 \mathrm{~h}$ ) or DNasetreated $\mathrm{HK}$ vaccine $(30 \mu \mathrm{g} / \mathrm{ml}$ of DNase I, at $37^{\circ} \mathrm{C}$ for $30 \mathrm{~min}$ ), and the expression of MHC II and B7.2 on the cells was monitored (D). 
immunized mice (FT) developed slightly reduced $(-12 \%)$ numbers of metastatic lung tumor nodules as compared to the control groups. However, the transfer of spleen cells from the HK-immunized mice resulted in a significant reduction $(-50 \%)$ in the number of metastatic tumor nodules within the lung (Figure 7A). The T cell involvement in the protection of mice against tumor cells was further confirmed via the in vivo depletion of $\mathrm{CD}^{+}$and $\mathrm{CD}^{+} \mathrm{T}$ cells from HK-immunized mice with mAbs GK1.5 and 2.43, respectively. As compared to the mice receiving isotype-matched control rat $\lg G$, the $\mathrm{CD}^{+} \mathrm{T}$ cell depleted mice showed an increase in the numbers of metastatic tumor nodules after the injection of live Colon26-M3.1 cells. A similar effect was noted in cases of $\mathrm{CD}^{+} \mathrm{T}$ cell depletion and the depletion of both $\mathrm{CD} 4^{+}$and $\mathrm{CD} 8^{+} \mathrm{T}$ cells completely abolished the protective effects of the HK vaccine (Figure 7B).

As the HK vaccine consistently produced profound immunization efficacy and because longterm memory $T$ cell generation is essential for the vaccine, we also attempted to ascertain whether mice who were tumor-protected by the HK vaccine might retain long-term immunity against rechallenge with the same tumor cells. Mice that had survived after the initial HK immunization and tumor challenge (in Figure 2) were re-injected with the same Colon26 tumor cells 100 days after the initial tumor challenge. Tumor growth was almost completely suppressed in the mice protected in the earlier tumor challenge (Figure 7C), thus suggesting the successful production of anti-tumor immune cells by the initial immunization with the HK vaccine.

\section{Strong stimulation of antigen-presenting cells by the HK vaccine}

Because the HK and FT vaccines from the same cell line showed a substantial difference with regard to the anti-tumor protective immune responses induced, we reasoned that the discrepancy might be attributable to differences in antigen presentation or antigenic interaction with antigenpresenting cells in two different forms of tumor antigen, rather than being caused by differences in the antigens themselves. To determine this, we immunized mice (i.p.) with identical amounts of the HK or FT vaccines and analyzed the peritoneal cells $5 \mathrm{~h}$ later. As compared to normal peritoneal cells, the HK-stimulated peritoneal cells showed a robust expansion of macrophages $\left(C D 11 b^{\text {int }}\right.$, $\left.\mathrm{CD}^{\circ}\right)^{-}$, as shown in Figure 8A. FT injection also induced macrophage expansion, but to a lesser degree. We then attempted to determine whether the HK and FT vaccines exert differential stimulation effects on cytokine production in antigenpresenting cells. It was well known that dendritic cells and macrophages play a central role in the control of immune response by producing various cytokines such as IL-12 and TNF- $\alpha$. Previously, Masse et al. (2002) reported that the injection of silica into peritoneal cavities can induce the recruitment of dendritic-like cells that expressed a significant level of CD80 and CD86 along with MHC class II. In this respect, we isolated silica-induced peritoneal DCs and thioglycollate- induced macrophages to measure IL-12 and TNF- $\alpha$ production by the APCs upon stimulation with FT and HK tumor cell extracts. As compared to the FT antigen, the HK antigen induced abundant production of IL-12 by the silica-induced DC-like cells (Figure 8B). Macrophages stimulated in a similar way also resulted in the generation of a large quantity of cytokines critical for the initiation of innate and adaptive immune responses, such as IL-12 and TNF- $\alpha$, when they were stimulated by the HK antigen. However, this effect was not as profound in cases in which the macrophages were stimulated by FT or FF antigens (Figure $8 \mathrm{C}$ ).

We then performed an experiment to determine the molecular nature of the strong adjuvant effect of the HK vaccine itself. Since the HK preparation adopted a quick and harsh boiling of liver tumor cells, we assumed that the molecular structures denatured by the harsh condition would trigger danger or stress signals to the immune system. In this case, proteins probably are the most likely candidates. To test this hypothesis, spleen cells

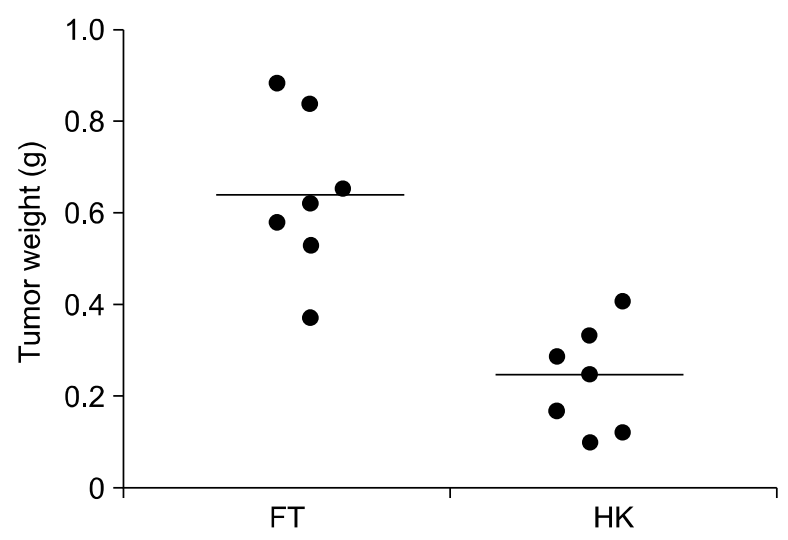

Figure 9. Therapeutic effects of the HK vaccine on tumor growth Colon26 tumor cells $\left(2 \times 10^{4} /\right.$ mouse) were inoculated s.c. on the right flanks of Babl/c mice and HK or FT vaccines were treated s.c. on the left flanks of the mice 1 and 5 days after tumor inoculation. The tumor masses were taken and weighed after two weeks of the last vaccine treatment. Each dot represents the mass of tumor taken from each mouse. Horizontal bars represent average values in each experimental group. 
were stimulated either with intact $\mathrm{HK}$ vaccine or proteinase-treated $\mathrm{HK}$ vaccine and the effect on the expression of MHC class II and the co-stimulatory molecule B7.2 by spleen cells were evaluated. When spleen cells were stimulated with $\mathrm{HK}$, MHC II and B7.2 expression was strongly induced, but proteinase-treated HK showed markedly reduced stimulation effects. DNase I treatment of the $\mathrm{HK}$ vaccine did not change the stimulation ability of the HK vaccine, thus suggesting that certain protein structures which were induced during the process of HK preparation might be responsible for the enhanced adjuvant effect of the HK vaccine (Figure 8D).

Finally, we evaluated the therapeutic effect of the HK vaccine by the injection of the HK vaccine into mice after tumor inoculation. Balb/c mice inoculated with Colon26 tumor cells were treated with HK or FT vaccines on days 1 and 5 after tumor inoculation. The tumor masses were taken and weighed after two weeks. The average size of tumor mass was about $40 \%$ in HK-treated mice compared to FT-treated mice (Figure 9).

Altogether, these results suggest that the high and abrupt heat treatment of live tumor cells dramatically increases the adjuvant effect of tumor antigens, which might be recognized by pattern recognition receptors, such as the TLRs expressed on APCs, and induces more Th1-type cytokine production.

\section{Discussion}

The development of an effective anti-tumor vaccine has been a critically important step in the field of anti-cancer immunotherapy. Strong immune responses are usually possible to induce via the introduction of a strong adjuvant, such as complete Freund's adjuvant, to a candidate vaccine. However, strong adjuvants tend to elicit unwanted side effects and cannot be employed in vaccines meant for use in humans. For the sake of safety, a vaccine that utilizes only the tumor antigen, with no added adjuvant, and can induce a sufficient protective immune response, would be most desirable. Recent progress in the field of tumor immunology has made it feasible for live tumor cells to be transfected with cytokines, such as IL-2 or IL-12, and then perhaps used as a tumor vaccine, which could induce profound $\mathrm{T}$ cell immune responses (Chang et al., 2005; Eguchi et al., 2005; Rittich et al., 2005; Shi et al., 2005; Grant et al., 2006). Although trials of such systems have proven effective in experiments, the prospect of injecting live tumor cells into an actual human body continues to be a subject of some debate. In order to allay these concerns, tumor vaccines containing no live cells and no adjuvant, but that still strongly induce anti-tumor cytotoxic and memory immune responses, must be developed in the future.

In this study, we were able to establish very effective anti-tumor immune responses in mice using heat-denatured tumor cells with no additives as a vaccine (HK vaccine). The observed rejection of challenged live tumor cells and the protection of immunized mice against tumors were far more effective than has been seen with other types of tumor antigens, including formaldehyde-fixed or repeated freeze-thawed tumor extracts. The vaccine effect was maintained for more than 100 days. Moreover, the HK vaccine showed a therapeutic effect on the tumor pre-challenged animals.

We initially attempted to determine whether the $\mathrm{HK}$ antigen could function as a good antigenic determinant for B-cell responses, thus inducing an increased generation of anti-tumor antibodies in immunized animals. Tumor cell surface antigenspecific antibody production after HK immunization, as compared to FT immunization, was found to be even lower in both melanoma and colon cancer cell lines (Figure 4A). These results show that epitopes on HK antigens may undergo conformational alterations as the result of denaturing high temperatures and thus do not function as a strong antigenic determinant for the surfaces of live tumor cells, although we did not rule out the possibility that the anti-tumor antibodies induced by HK are qualitatively stronger than those induced by FT.

Rather, this profound immunogenic effect appears to be predicated on the efficient stimulation of APCs by the tumor antigens constituting the HK vaccine. Macrophage and dendritic cells coming into contact with $\mathrm{HK}$ antigens upregulated the surface expression of the co-stimulatory molecule $B 7.2$, which is critical for the activation of naïve $T$ cells (Coyle and Gutierrez-Ramos, 2001). Moreover, these APCs secrete a substantial quantity of IL-12 and TNF- $\alpha$, both of which are key cytokines for the inflammatory response and a Th1 immune response (Langrish et al., 2004; Cantor and Haskins, 2005). Although the HK antigen induced profound IL-12 expression in macrophages and DCs, the NK cells were not directly involved in the protective response. This was rather surprising for two reasons. First, since the depletion of NK cells in the unimmunized control group resulted in a marked increase in the numbers of lung tumor nodules, implicating the involvement of NK cells in antitumor responses under physiological conditions, it might be reasonable to expect a decreased 
anti-tumor response in NK cell-depleted HK-immunized mice. Second, since IL-12 is known to be a strong activator of NK cells, these cells might also be stimulated by cytokines induced by the HK antigens. Conversely, these results indicate that a strong adaptive immune response induced by HK antigens might overwhelm the effects of NK cells under our experimental conditions. Thus, the depletion of NK cells did not result in any marked differences in the rejection of tumor cells.

What, then, would be the molecular differences between protective $\mathrm{HK}$ antigens and the less protective (or non-protective) FF and FT antigens? One possibility might be molecules that are newly induced during the preparation of the antigen. As these preparation steps are stressful to the cells, stress-induced molecules, which are often inflammation inducers, could be produced and might function as immune stimulators. However, new gene expression does not seem feasible, taking into consideration the time and harsh denaturing conditions of the antigen preparation associated with the HK vaccine. For the same reason, the activation of some pre-existing stress gene product is also unlikely. The second possibility is that the denaturation or modification of tumor antigens by boiling might expose an immunogenic moiety which was normally hidden. Boiling destroys the three-dimensional structures of protein antigens and might cause the exposure of hydrophobic residues. Recent studies have revealed that the hydrophobic portions of proteins tend to be strong immune stimulators (Seong and Matzinger, 2004). Currently, we are unable to precisely confirm the molecular nature of the immunostimulatory factors of the $\mathrm{HK}$ vaccine. However, the observed signs of reduced APC stimulation, including lower levels of MHC class II and the B7 co-stimulatory molecule expression as induced by the protease-treated HK vaccine, but not by the nuclease or glucosidasetreated HK antigens (data not shown), suggests that these stimulatory molecules are protein antigens and are modified to function as stimulators of APC activation during the preparation of the HK antigen. Stresses, such as acute denaturing high temperature and exposure of the internal hydrophobic region of proteins, might be perceived as immunological challenges by the APCs. The immediate activation and increase in peritoneal macrophages upon the injection of $\mathrm{HK}$ antigens, as shown in Figure $8 \mathrm{~A}$, and the prompt secretion of inflammatory cytokines, including IL-12 and TNF- $\alpha$ by purified DCs and macrophages upon in vitro HK antigen stimulation (Figure $8 \mathrm{~B}$ and $\mathrm{C}$ ), suggests that $\mathrm{HK}$ antigens are recognized by APCs and induce the prompt activation of the innate immune system, consequently promoting tumor antigenspecific adaptive immune responses. In addition, activation of macrophages by the HK vaccine was not the result of endotoxin contamination, since the addition of $10 \mu \mathrm{g} / \mathrm{ml}$ polymyxin (PM) in the culture did not change the IL-12 and TNF- $\alpha$ production of HK-stimulated macrophages, but did inhibit IL-12/ TNF- $\alpha$ production of LPS stimulated macrophages (data not shown).

APCs express a variety of pattern recognition receptors for the perception of harmful immunological challenges and promptly induce proinflammatory responses, including inflammatory cytokine secretion and chemokine release. Among them, Toll-like receptors (TLRs) have been demonstrated to participate in the recognition of pathogens by the innate immune system (Iwasaki and Medzhitov, 2004). TLRs sample the contents of the phagosome taken up by the APCs and establish a combinatorial repertoire to discriminate among the large number of pathogen and stress-related molecular patterns observed in nature. Thus, it remains possible that the denatured form of self-molecules, which were introduced during the preparation of the HK vaccine, might be detected by TLRs. Speidel et al. (1997) also showed that heat-denatured protein antigens were able to enhance antigenspecific CTL responses. Interestingly in their paper, stronger minor antigen $\mathrm{H}$-specific CTL response was induced when the recipients were immunized with fresh spleen cells compared to heat-killed spleen cell-immunization. The obvious discrepancy with us seems to mainly come from allo-specific response in their experiments. Because they immunized $\mathrm{B} 6\left(\mathrm{H}-2^{\mathrm{b}}\right)$ recipients with fresh or heatkilled Balb/c $\left(\mathrm{H}-2^{d}\right)$ spleen cells and monitored CTL activity against Balb/b $\left(\mathrm{H}-2^{\mathrm{b}}\right)$ target cells, the immunized fresh spleen cells served during primary immune responses as target cells of allospecific responses, which can produce stronger inflammatory condition compared to that of heat killed spleen cells. Nevertheless, the spleen cells of recipients immunized with heat-killed spleen cells showed antigen-specific secondary CTL activity as strong as that of fresh spleen cell-immunized recipients after five days of in vitro re-stimulation.

In our experiment, however, tumor cells used for the vaccines were syngeneic to the recipients and they were all killed and extracted no matter what methods were employed for the vaccine preparation. By this reason, rather than serving as target cells, tumor vaccines must be processed and presented to MHC I molecules by professional APCs to induced CTL responses. Although the experimental conditions were different, our results along with Speidel et al. (1997) clearly indicated that 
tumor cell extracts can be processed and presented to not only $\mathrm{CD} 4^{+} \mathrm{T}$ cells but also $\mathrm{CD} 8^{+} \mathrm{T}$ cells through cross priming as were shown by target cell-specific CTL responses. For the cross priming of $\mathrm{CD}^{+} \mathrm{T}$ cells by the extracellular antigens, phagocytosed antigens need to be processed either in the cytosol or the antigens processed in the lysosomal compartment need to be transported to endoplasmic reticulum, where cross presentation to the MHC I occurs (Shen and Rock, 2006). Thus, it is also possible that the difference of antigen preparation might involve in the enhanced cross presentation of tumor antigen to MHC class I molecules and result in difference in adjuvant effects. It would be of interest to investigate the exact molecule or molecular patterns that confer strong adjuvant effects to the HK vaccine.

Overall, our results show that the HK vaccine is a strong immunostimulatory antigen for anti-tumor immune responses and could be a material for the creation of a safe cancer vaccine. Its application as the single constituent of a tumor vaccine, in the absence of any adjuvant or feeding antigen for a DC-based tumor vaccine, would improve the efficacy of the tumor vaccines.

\section{Acknowledgements}

This work was supported by a grant (R01-2006-00010125-0) from the Korea Science and Engineering Foundation, a grant (10693M0207551) from the Seoul RNBD Program and a grant (03-PJ1-PG1-CH01-0001) from the Ministry of Health and Welfare, Korea Health 21 R\&D project.

\section{References}

Ahmad M, Rees RC, Ali SA. Escape from immunotherapy: possible mechanisms that influence tumor regression/ progression. Cancer Immunol Immunother 2004;53:844-54

Appleman LJ, Boussiotis VA. T cell anergy and costimulation. Immunol Rev 2003;192:161-80

Avigan D. Dendritic cell-tumor fusion vaccines for renal cell carcinoma. Clin Cancer Res 2004;10:6347S-52S

Banchereau J, Briere F, Caux C, Davoust J, Lebecque S, Liu YJ, Pulendran B, Palucka K. Immunobiology of dendritic cells. Annu Rev Immunol 2000;18:767-811

Banchereau J, Palucka AK. Dendritic cells as therapeutic vaccines against cancer. Nat Rev Immunol 2005;5:296-306

Cantor J, Haskins K. Effector function of diabetogenic CD4 Th1 T cell clones: a central role for TNF-alpha. J Immunol 2005;175:7738-45

Chang J. Efficient amplification of melanoma-specific CD8+ $\mathrm{T}$ cells using artificial antigen presenting complex. Exp Mol

\section{Med 2006;38:591-8}

Chang MR, Lee WH, Choi JW, Park SO, Paik SG, Kim YS. Antitumor immunity induced by tumor cells engineered to express a membrane-bound form of IL-2. Exp Mol Med $2005 ; 37: 240-9$

Cheuk AT, Chan L, Czepulkowski B, Berger SA, Yagita H, Okumura K, Farzaneh F, Mufti GJ, Guinn BA. Development of a whole cell vaccine for acute myeloid leukaemia. Cancer Immunol Immunother 2006;55:68-75

Copier J, Dalgleish A. Overview of tumor cell-based vaccines. Int Rev Immunol 2006;25:297-319

Coyle AJ, Gutierrez-Ramos JC. The expanding B7 superfamily: increasing complexity in costimulatory signals regulating T cell function. Nat Immunol 2001;2:203-9

Cuenca A, Cheng F, Wang H, Brayer J, Horna P, Gu L, Bien $\mathrm{H}$, Borrello IM, Levitsky HI, Sotomayor EM. Extra-lymphatic solid tumor growth is not immunologically ignored and results in early induction of antigen-specific T-cell anergy: dominant role of cross-tolerance to tumor antigens. Cancer Res 2003;63:9007-15

Eguchi J, Kuwashima N, Hatano M, Nishimura F, Dusak JE, Storkus WJ, Okada H. IL-4-transfected tumor cell vaccines activate tumor-infiltrating dendritic cells and promote type-1 immunity. J Immunol 2005;174:7194-201

Emens LA. Roadmap to a better therapeutic tumor vaccine. Int Rev Immunol 2006;25:415-43

Garcia-Lora A, Algarra I, Garrido F. MHC class I antigens, immune surveillance, and tumor immune escape. J Cell Physiol 2003;195:346-55

Gattinoni L, Powell DJ Jr, Rosenberg SA, Restifo NP. Adoptive immunotherapy for cancer: building on success. Nat Rev Immunol 2006;6:383-93

Grant JF, Iwasawa T, Sinn HW, Siemens DR, Griffith TS, Takacs EB, Ratliff TL. Induction of protective immunity to RM-1 prostate cancer cells with ALVAC-IL-2/IL-12/TNFalpha combination therapy. Int J Cancer 2006;119:2632-41

Gutzmer R, Li W, Sutterwala S, Lemos MP, Elizalde JI, Urtishak SL, Behrens EM, Rivers PM, Schlienger K, Laufer TM, Eck SL, Marks MS. A tumor-associated glycoprotein that blocks MHC class II-dependent antigen presentation by dendritic cells. J Immunol 2004;173:1023-32

Hirst WJ, Buggins A, Darling D, Gaken J, Farzaneh F, Mufti GJ. Enhanced immune costimulatory activity of primary acute myeloid leukaemia blasts after retrovirus-mediated gene transfer of B7.1. Gene Ther 1997;4:691-9

Hong C, Lee H, Oh M, Kang CY, Hong S, Park SH. CD4+ T cells in the absence of the CD8+ cytotoxic T cells are critical and sufficient for NKT cell-dependent tumor rejection. J Immunol 2006;177:6747-57

Iwasaki A, Medzhitov R. Toll-like receptor control of the adaptive immune responses. Nat Immunol 2004;5:987-95

Korbelik M, Sun J. Photodynamic therapy-generated vaccine for cancer therapy. Cancer Immunol Immunother 2006;55:900-9

Langrish CL, McKenzie BS, Wilson NJ, de Waal Malefyt R, 
Kastelein RA, Cua DJ. IL-12 and IL-23: master regulators of innate and adaptive immunity. Immunol Rev 2004;202: 96-105

Li H, Niederkorn JY, Neelam S, Mayhew E, Word RA, McCulley JP, Alizadeh $\mathrm{H}$. Immunosuppressive factors secreted by human amniotic epithelial cells. Invest Ophthalmol Vis Sci 2005;46:900-7

Masse D, Voisine C, Henry F, Cordel S, Barbieux I, Josien R, Meflah K, Gregoire M, Lieubeau B. Increased vaccination efficiency with apoptotic cells by silica-induced, dendritic-like cells. Cancer Res 2002;62:1050-6

Matzinger P. The JAM test. A simple assay for DNA fragmentation and cell death. J Immunol Methods 1991;145: 185-92

Nouri-Shirazi M, Banchereau J, Fay J, Palucka K. Dendritic cell based tumor vaccines. Immunol Lett 2000a;74:5-10

Nouri-Shirazi M, Banchereau J, Bell D, Burkeholder S, Kraus ET, Davoust J, Palucka KA. Dendritic cells capture killed tumor cells and present their antigens to elicit tumor-specific immune responses. J Immunol 2000b;165:3797-803

Ogino T, Bandoh N, Hayashi T, Miyokawa N, Harabuchi Y, Ferrone $\mathrm{S}$. Association of tapasin and HLA class I antigen down-regulation in primary maxillary sinus squamous cell carcinoma lesions with reduced survival of patients. Clin Cancer Res 2003;9:4043-51

Paczesny S, Ueno H, Fay J, Banchereau J, Palucka AK. Dendritic cells as vectors for immunotherapy of cancer. Semin Cancer Biol 2003;13:439-47

Prasad SJ, Farrand KJ, Matthews SA, Chang JH, McHugh RS, Ronchese F. Dendritic cells loaded with stressed tumor cells elicit long-lasting protective tumor immunity in mice depleted of CD4+CD25+ regulatory T cells. J Immunol 2005; $174: 90-8$

Rittich S, Duskova M, Mackova J, Pokorna D, Jinoch P, Smahel M. Combined immunization with DNA and transduced tumor cells expressing mouse GM-CSF or IL-2. Oncol Rep 2005;13:311-7

Rosenberg SA, Yang JC, Restifo NP. Cancer immunotherapy: moving beyond current vaccines. Nat Med 2004; 10:909-15

Seliger B. Strategies of tumor immune evasion. BioDrugs

\section{5; $19: 347-54$}

Seong SY, Matzinger P. Hydrophobicity: an ancient damageassociated molecular pattern that initiates innate immune responses. Nat Rev Immunol 2004;4:469-78

Shen L, Rock KL. Priming of T cells by exogenous antigen cross-presented on MHC class I molecules. Curr Opin Immunol 2006;18:85-91

Shi M, Su L, Hao S, Guo X, Xiang J. Fusion hybrid of dendritic cells and engineered tumor cells expressing interleukin-12 induces type 1 immune responses against tumor. Tumori 2005;91:531-8

Speidel K, Osen W, Faath S, Hilgert I, Obst R, Braspenning J, Momburg F, Hammerling GJ, Rammensee HG. Priming of cytotoxic $T$ lymphocytes by five heat-aggregated antigens in vivo: conditions, efficiency, and relation to antibody responses. Eur J Immunol 1997;27:2391-9

Todryk S, Melcher AA, Hardwick N, Linardakis E, Bateman A, Colombo MP, Stoppacciaro A, Vile RG. Heat shock protein 70 induced during tumor cell killing induces Th1 cytokines and targets immature dendritic cell precursors to enhance antigen uptake. J Immunol 1999;163:1398-408

Toutirais O, Chartier P, Dubois D, Bouet F, Leveque J, Catros-Quemener V, Genetet N. Constitutive expression of TGF-beta1, interleukin- 6 and interleukin- 8 by tumor cells as a major component of immune escape in human ovarian carcinoma. Eur Cytokine Netw 2003;14:246-55

Vitale M, Pelusi G, Taroni B, Gobbi G, Micheloni C, Rezzani $\mathrm{R}$, Donato $\mathrm{F}$, Wang $\mathrm{X}$, Ferrone S. HLA class I antigen down-regulation in primary ovary carcinoma lesions: association with disease stage. Clin Cancer Res 2005;11: 67-72

Wang Y, Kelly CG, Singh M, McGowan EG, Carrara AS, Bergmeier LA, Lehner T. Stimulation of Th1-polarizing cytokines, C-C chemokines, maturation of dendritic cells, and adjuvant function by the peptide binding fragment of heat shock protein 70. J Immunol 2002;169:2422-9

Witham TF, Villa L, Yang T, Pollack IF, Okada H, Robbins PD, Chambers WH. Expression of a soluble transforming growth factor-beta (TGFbeta) receptor reduces tumorigenicity by regulating natural killer (NK) cell activity against $9 \mathrm{~L}$ gliosarcoma in vivo. J Neurooncol 2003;64:63-9 